\title{
What role for One Health in the COVID-19 pandemic?
}

\author{
Arne Ruckert $^{1}$ (D) $\cdot{\text { Kate } \text { Zinszer }^{2} \text { (D) } \cdot \text { Christina Zarowsky }^{2} \text { (D) } \cdot \text { Ronald Labonté }^{1} \text { (D) } \cdot \text { Hélène Carabin }}^{3}$ (D)
}

Received: 14 May 2020 / Accepted: 23 August 2020 / Published online: 9 September 2020

(C) The Canadian Public Health Association 2020

\begin{abstract}
This commentary discusses the contributions that One Health $(\mathrm{OH})$ principles can make in improving the global response to the COVID-19 pandemic. We highlight four areas where the application of $\mathrm{OH}$ has the potential to significantly improve the governance of infectious diseases in general, and of COVID-19 in particular. First, more integrated surveillance infrastructure and monitoring of the occurrence of infectious diseases in both humans and animals can facilitate the detection of new infectious agents sharing similar genotypes across species and the monitoring of the spatio-temporal spread of such infections. This knowledge can guide public and animal health officials in their response measures. Second, application of the $\mathrm{OH}$ approach can improve coordination and active collaboration among stakeholders representing apparently incompatible domains. Third, the $\mathrm{OH}$ approach highlights the need for an effective institutional landscape, facilitating adequate regulation of hotspots for transmission of infectious agents among animals and humans, such as live animal markets. And finally, $\mathrm{OH}$ thinking emphasizes the need for equitable solutions to infectious disease challenges, suggesting that policy response mechanisms and interventions need to be reflective of the disproportionate disease burdens borne by vulnerable and marginalized populations, or by persons providing health care and other essential services to those sick.
\end{abstract}

\section{Résumé}

Ce commentaire décrit comment le concept d'Une seule santé (USS) pourrait améliorer la réponse à la pandémie de la COVID19. Nous soulignons quatre domaines où l'application de la USS pourrait potentiellement améliorer de façon significative la gouvernance des maladies infectieuses en général et de la COVID-19 en particulier. Premièrement, l'intégration de systèmes de surveillance et de suivi tant humain qu'animal peut faciliter la détection de nouveaux agents infectieux dont les génotypes sont similaires, et le suivi de la distribution spatio-temporelle des cas d'infections. De tels systèmes intégrés permettent aux instances de santé humaine et animale de mieux planifier leur réponse sanitaire. Deuxièmement, l'application de l'approche USS peut faciliter la collaboration entre des parties prenantes qui, à première vue, oeuvrent dans des domaines incompatibles. Troisièmement, l'approche USS souligne la nécessité pour une structure institutionnelle efficace permettant la mise en place de réglementation adéquate pour contrer la transmission ponctuelle d'agents infectieux parmi les animaux et les humains, comme par exemple dans le cas de marchés d'animaux vivants. Finalement, la pensée USS souligne le besoin pour des solutions équitables aux défis que posent les maladies infectieuses, et donc pour des mécanismes de réponses politiques et interventions qui reflètent le fardeau disproportionné que portent surtout les populations marginalisées et plus vulnérables, ou encore les personnes qui traitent et prennent en charge les malades.

Arne Ruckert

aruckert@uottawa.ca

1 School of Epidemiology and Public Health, Faculty of Medicine, University of Ottawa, 600 Peter Morand Crescent, Ottawa, ON K1G 3Z7, Canada

2 Department of Social and Preventive Medicine, Université de Montréal, Montreal, QC H3N 1X9, Canada

3 Department of Pathology and Microbiology, Faculty of Veterinary Medicine, Université de Montréal, Saint-Hyacinthe, QC J2S 2M2, Canada 
Keywords COVID-19 pandemic $\cdot$ One Health approach $\cdot$ Global governance $\cdot$ Infectious diseases $\cdot$ Health equity

Mots-clés Pandémie COVID-19 · approche Une seule santé · gouvernance au niveau mondial · maladies infectieuses · équité en santé

The COVID-19 pandemic has reinforced the relevance of One Health principles in the global governance of infectious diseases, in particular in international efforts to prevent and contain zoonotic diseases. The risk of emergence of infectious agents capable of jumping the species barrier is increasing, with the ability of novel infectious agents to spread rapidly around the globe due to increased travel and trade (Jones et al. 2008). These diseases can have devastating impacts on communities, health systems, and economies, resulting in years of social and economic recovery (Gatiso et al. 2018). The occurrence and subsequent spread of a zoonotic agent can be seen as a result of various challenges in local, national, and global governance arrangements (Figuié 2014).

One Health has been defined by the WHO as "an approach to designing and implementing programmes, policies, legislation and research in which multiple sectors communicate and work together to achieve better public health outcomes" (WHO 2020). It recognizes that the health and well-being of humans, animals and the environment are intricately linked. In practice, this means that experts from a range of sectors, notably human health, animal health, plant health and the environment, work together in building a response infrastructure that emphasizes the sharing of information and the coordination of actions across multiple sectors. The One Health approach resembles other public health initiatives that attempt to break down disciplinary or sectoral silos, such as whole-ofgovernment or health-in-all-policies approaches, or more recent calls for prioritizing eco-health or planetary health. It differs, however, by focusing on how competing interests such as agricultural productivity, farm livelihoods, animal health and the health of populations far removed from the farm must be balanced over a long period (Zumla et al. 2016). This poses difficult governance and implementation challenges as the spectre of imminent health catastrophe is seldom present at the pre-epidemic stage when action is most crucial.

The practical implementation of the One Health approach remains challenging for most nations and globally (El Zowalaty and Järhult 2020; Lee and Brumme 2013), creating an important need for more leadership and knowledge on how best to operationalize its principles in practice. To that end, we are currently building the One Health Network for the Global Governance of Infectious Diseases and Antimicrobial Resistance (Global 1HN, accessible at http://globallhn.ca/), funded by the Canadian Institutes of Health Research (CIHR Grant number 167542), to strengthen Canadian leadership in this policy space. To strengthen its integrative approach to
One Health, the network (to date) has active members from a range of disciplines, spanning the social sciences (e.g., political science, anthropology, economics, sociology, law), veterinary health sciences (e.g., animal health), human health (e.g., clinical epidemiology, public health sciences, health behaviourism), environmental health sciences (e.g., eco-economics, sustainable development studies), and crosscutting disciplines (e.g., infectious disease epidemiology, implementation research).

The network consists of four research streams. The first stream at Université de Montréal focuses on building and sustaining integrated disease surveillance infrastructure. Systematically collecting data on the occurrence of infectious diseases, and related behaviours, in both humans and animals, can contribute to developing models to estimate the probability that a new zoonotic agent emerges and enters Canada (or any other country or region). Such systematic monitoring also facilitates the tracking of the spread of infection while providing early warning to human and animal health officials for response measures. Current disease surveillance systems in many countries (including Canada) remain challenged in their ability to detect and monitor emerging zoonotic diseases and there is little evidence on what an effective, integrated One Health surveillance system would look like (Wendt et al. 2015). As part of CIHR's rapid funding coronavirus response call, we lead a collaboration with the Public Health Agency of Canada (PHAC)'s Internet-based Surveillance Informing Global Health Threats (InSIGHT) project to develop machine learning algorithms. These algorithms will assist in the rapid detection of COVID-19 cases and measurement of behaviours towards public health recommendations in real time using electronic media. The CIHR project, complemented with funds from the Canadian Safety and Security Program, is specifically evaluating whether social media data (e.g., Twitter) could be used as a tool to improve the speed at which local outbreaks are identified, and to identify reluctance to follow public health recommendations. Data from reports on cases in domestic and wild animals are also included. A near real-time and easily usable surveillance system of the spatio-temporal distribution of cases and behaviours is essential to controlling the spread of emerging infections.

Second is the challenge of coordination and active collaboration required between various agencies for a unified, timely response to zoonotic infectious disease outbreak (Osterhaus et al. 2020). This is not only required at the local level but also for global response efforts to minimize the likelihood of 
pandemic potential. This challenge can arise from a lack of mechanisms for inter-agency collaboration and an absence of operational support for a coordinated response (WHO, FAO, and OIE 2019). This was apparent in Canada's response to SARS in 2002, where a lack of coordination between fragmented government departments impeded the ability for an effective response, and ultimately led to the creation of PHAC (Public Health Agency of Canada 2004). A related area where collaboration remains problematic is in finding the right balance between private and public sector involvement in the governance of vaccine development to ensure that vaccines come to market rapidly while also being equitably accessible. This issue continues to vex current efforts to find a SARS-CoV-2 vaccine, further complicated by what has been called 'vaccine nationalism' by governments with the financial means to dominate advance purchase agreements. Research activities at the University of Calgary explore how recent government-sponsored research interacted with commercial exploitation for infectious diseases vaccination, to inform licensing conditions for COVID-19 treatments and promote more effective global mechanisms for fair distribution (Hollis and Busby 2020).

Third, any effective global response to infectious diseases will require an adequate institutional landscape that facilitates a coordinated One Health governance response (Interagency Coordination Group on Antimicrobial Resistance 2018). Governance of a multi-species approach with an environmental component to the monitoring of the infection in companion animals and humans is also lacking, even though several instances of spread of COVID-19 to animals and back to humans have been reported. The focus of concern with the current pandemic has been on governance of live animal markets, the presumed source of the COVID-19 outbreak (Maron 2020). This can be particularly challenging in low- and middle-income countries and remote regions where such markets are important in food distribution systems, as resources to detect and monitor infectious diseases are often scarce (World Health Organization 2007) and changing socio-economic contexts may increase the likelihood of novel zoonoses developing. The third research stream at York University aims to better understand the differing regulatory environments that govern such markets as a crucial first step in assessing the role of local or national-level institutions in minimizing zoonotic disease risk. A rapid environmental scan of the regulatory environment of such markets is intended to identify both novel regulations and the means through which they could be implemented at the global and national levels. It will also examine the degree of enforcement of existing regulations, and socially and culturally acceptable changes in practice to reduce the likelihood of future zoonotic disease transmission without necessarily requiring stringent enforcement measures.

Finally, pandemics are inherently disequalizing, disproportionately affecting individuals and groups in vulnerable conditions. This is already widely visible in the current COVID-19 pandemic, with the most vulnerable populations strongly overrepresented in case fatalities globally (Eligon et al. 2020). The gender dynamics of the pandemic have already been widely discussed, with acknowledgements that while men are more likely to die from COVID-19, women are more likely to experience negative health repercussions via social determinants of health pathways (Bali et al. 2020). In order to reduce worsening of health inequities during a pandemic, our detection and response mechanisms and interventions need to be reflective of the disproportionate disease burdens borne by vulnerable and marginalized populations, or by persons placed at higher risk of infection without the adequate protection measures in place (e.g., certain types of healthcare workers and other essential service providers). It is for this reason that a team at the University of Ottawa is studying how health equity concerns are integrated into COVID-19 policy response in Canada, Brazil, Ecuador, Mexico and Rwanda, and what equity impact specific policy choices will have, both in the short term through the operational policy response and in the longer term through social determinants of health pathways. This will lead to policy recommendations on how to improve protection of vulnerable populations in current and future infectious disease outbreaks, both through attention to the socio-historical conditions that create vulnerabilities and recognition of the knowledge and capabilities that many marginalized communities possess that should inform measures to prevent or mitigate the health harms arising from such outbreaks. However, as has been recently argued, $\mathrm{OH}$ concerns surrounding equity must go beyond solely focusing on the human element, and should include rethinking social justice through a multi-species lens (Celermajer et al. 2020). As elsewhere in our network's activities, this requires combining insights from the human and animal health, environmental, and social sciences, and integrating a variety of sectors (public, civil society and business) to develop and apply $\mathrm{OH}$ relevant approaches.

\section{Conclusion}

While the One Health approach is considered crucial to address governance challenges of zoonotic diseases and is widely supported in theory, its implementation in practice remains quite limited. Our Global-1HN network intends to facilitate wider awareness and implementation of a One Health approach to governance of infectious diseases through new research and comparative case studies, and a deliberate and reflexive effort to ensure cross-disciplinarity in all of its activities. Our findings directly feed into the policy-making process though high-level knowledge users, including Deputy Chief Public Health Officer Dr. Howard Njoo. We encourage others to collaborate with us in new research initiatives and through 
our emerging Community of Practice, which includes actors from local to global governance levels, in this new public health endeavour.

\section{Compliance with ethical standards}

Conflict of interest The authors declare that they have no conflict of interest.

\section{References}

Bali, S., Dhatt, R., Lal, A., Jama, A., Van Daalen, K., Sridhar, D., \& Gender and COVID-19 Working Group, \& Women in Global Health, and Gender and COVID-19 Working Group. (2020). Off the back burner: diverse and gender-inclusive decision-making for COVID-19 response and recovery. BMJ Global Health, 5(5). https://doi.org/10.1136/bmjgh-2020-002595.

Celermajer, D., Chatterjee, S., Cochrane, A., Fishel, S., Neimanis, A., O'Brien, A., Reid, S., Srinivasan, K., Schlosberg, D., \& Waldow, A. (2020). Justice through a multispecies lens. Contemporary Political Theory. https://doi.org/10.1057/s41296-020-00386-5.

El Zowalaty, M. E., \& Järhult, J. D. (2020). From SARS to COVID-19: a previously unknown SARS- related coronavirus (SARS-CoV-2) of pandemic potential infecting humans - call for a One Health approach. One Health, 9, 100124. https://doi.org/10.1016/j.onehlt. 2020.100124

Eligon, J., Burch, A. D. S., Searcey, D., \& Jr, R. A. O. (2020). Black Americans face alarming rates of coronavirus infection in some states. The New York Times. https://www.nytimes.com/2020/04/ 07/us/coronavirus-race.html . Accessed 17 Apr 2020.

Figuié, M. (2014). Towards a global governance of risks: international health organisations and the surveillance of emerging infectious diseases. Journal of Risk Research, 17(4), 469-483.

Gatiso, T. T., Ordaz-Németh, I., Grimes, T., Lormie, M., Tweh, C., Kühl, H. S., \& Junker, J. (2018). The impact of the Ebola virus disease (EVD) epidemic on agricultural production and livelihoods in Liberia. PLoS Neglected Tropical Diseases, 12(8), e0006580. https://doi.org/10.1371/journal.pntd.0006580.

Hollis, A., Busby, C. (2020). International fund could drive equitable development of COVID-19 vaccine. Policy Options. https:// policyoptions.irpp.org/magazines/april-2020/international-fundcould-drive-equitable-development-of-covid-19-vaccine/. Accessed 11 May 2020.

Interagency Coordination Group on Antimicrobial Resistance. (2018). Future global governance for antimicrobial resistance. https:// www.who.int/antimicrobial-resistance/interagency-coordination-
group/IACG_Future_global_governance_for_AMR_120718.pdf. Accessed 4 May 2020.

Jones, K. E., Patel, N. G., Levy, M. A., Storeygard, A., Balk, D., Gittleman, J. L., \& Daszak, P. (2008). Global trends in emerging infectious diseases. Nature, 451(7181), 990-993. https://doi.org/10. 1038/nature06536.

Lee, K., \& Brumme, Z. L. (2013). Operationalizing the One Health approach: the global governance challenges. Health Policy and Planning, 28(7), 778-785. https://doi.org/10.1093/heapol/czs127.

Maron, D. F. (2020). "Wet markets" likely launched the coronavirus. Here's what you need to know. Animals. https://www. nationalgeographic.com/animals/2020/04/coronavirus-linked-tochinese-wet-markets/. Accessed 27 Apr 2020.

Osterhaus, A. D. M. E., Vanlangendonck, C., Barbeschi, M., Bruschke, C. J. M., Christensen, R., Daszak, P., de Groot, F., Doherty, P., Drury, P., Gmacz, S., Hamilton, K., Hart, J., Katz, R., Longuet, C., McLeay, J., Morelli, G., Schlundt, J., Smith, T., Suri, S., et al. (2020). Make science evolve into a One Health approach to improve health and security: a white paper. One Health Outlook, 2(1), 6. https://doi.org/10.1186/s42522-019-0009-7.

Public Health Agency of Canada (2004). Learning from SARS: renewal of public health in Canada - building capacity and coordination [assessments;guidance]. Aem. https://www.canada.ca/en/publichealth/services/reports-publications/learning-sars-renewal-publichealth-canada/chapter-5-building-capacity-coordination-nationalinfectious-disease-surveillance.html. Accessed 27 Apr 2020.

Wendt, A., Kreienbrock, L., \& Campe, A. (2015). Zoonotic disease surveillance - inventory of systems integrating human and animal disease information. Zoonoses and Public Health, 62(1), 61-74. https://doi.org/10.1111/zph.12120.

WHO (2020). One health. WHO. http://www.who.int/features/qa/onehealth/en/. Accessed 17 Apr 2020.

WHO, FAO, \& OIE (2019). Taking a multisectoral One Health approach: a tripartite guide to addressing zoonotic diseases in countries (p. 166). WHO. http://www.fao.org/3/ca2942en/ ca2942en.pdf. Accessed 17 Apr 2020.

World Health Organization. (2007). New rules on international public health security. Bulletin of the World Health Organization, 85(6), 428-430. https://doi.org/10.2471/BLT.07.100607.

Zumla, A., Dar, O., Kock, R., Muturi, M., Ntoumi, F., Kaleebu, P., Eusebio, M., Mfinanga, S., Bates, M., Mwaba, P., Ansumana, R., Khan, M., Alagaili, A. N., Cotten, M., Azhar, E. I., Maeurer, M., Ippolito, G., \& Petersen, E. (2016). Taking forward a 'One Health' approach for turning the tide against the Middle East respiratory syndrome coronavirus and other zoonotic pathogens with epidemic potential. International Journal of Infectious Diseases, 47, 5-9. Scopus. https://doi.org/10.1016/j.ijid.2016.06.012.

Publisher's note Springer Nature remains neutral with regard to jurisdictional claims in published maps and institutional affiliations. 